\title{
Dodecapus: An MR-compatible system for somatosensory stimulation
}

\author{
Ruey-Song Huang ${ }^{\mathrm{a}, \mathrm{b}}$ and Martin I. Sereno ${ }^{\mathrm{a}, *}$ \\ ${ }^{a}$ Department of Cognitive Science 0515, University of California San Diego, La Jolla, CA 92093-0515, USA \\ ${ }^{\mathrm{b}}$ Swartz Center for Computational Neuroscience, Institute for Neural Computation, University of California San Diego, La Jolla, CA 92093-0961, USA
}

Received 17 May 2006; revised 3 October 2006; accepted 11 October 2006

Available online 19 December 2006

\begin{abstract}
Somatotopic mapping of human body surface using fMRI is challenging. First, it is difficult to deliver tactile stimuli in the scanner. Second, multiple stimulators are often required to cover enough area of the complex-shaped body surface, such as the face. In this study, a computer-controlled pneumatic system was constructed to automatically deliver air puffs to 12 locations on the body surface through an MR-compatible manifold (Dodecapus) mounted on a head coil inside the scanner bore. The timing of each air-puff channel is completely programmable and this allows systematic and precise stimulation on multiple locations on the body surface during functional scans. Three two-condition block-design "Localizer" paradigms were employed to localize the cortical representations of the face, lips, and fingers, respectively. Three "Phase-encoded" paradigms were employed to map the detailed somatotopic organizations of the face, lips, and fingers following each "Localizer" paradigm. Multiple somatotopic representations of the face, lips, and fingers were localized and mapped in primary motor cortex (MI), ventral premotor cortex (PMv), polysensory zone (PZ), primary (SI) and secondary (SII) somatosensory cortex, parietal ventral area (PV) and $7 \mathrm{~b}$, as well as anterior and ventral intraparietal areas (AIP and VIP). The Dodecapus system is portable, easy to setup, generates no radio frequency interference, and can also be used for EEG and MEG experiments. This system could be useful for non-invasive somatotopic mapping in both basic and clinical studies.
\end{abstract}

(C) 2006 Published by Elsevier Inc.

Keywords: fMRI; Somatosensory; Air puffs; Face; Lips; Fingers; Phaseencoded somatotopy

\section{Introduction}

Topographic mapping is a fundamental organizing principle of sensory systems in the brain. In primary visual cortex (V1), adjacent locations receive inputs from adjacent photoreceptors on the retina, which is known as retinotopy. Similarly, different frequencies of sounds are represented in a tonotopic map in auditory cortex. Functional magnetic resonance imaging (fMRI)

\footnotetext{
* Corresponding author. Fax: +1 8585341128.

E-mail address: sereno@cogsci.ucsd.edu (M.I. Sereno).

Available online on ScienceDirect (www.sciencedirect.com).
}

has been used to non-invasively reveal topographic maps in visual, auditory, somatosensory, and parietal cortices (Overduin and Servos, 2004; Sereno et al., 1995, 2001; Sereno and Tootell, 2005; Servos et al., 1998, 1999; Talavage et al., 2004). Somatotopic mapping is more difficult than retinotopy and tonotopy, however. One major limitation for an fMRI experiment is that the physical stimulus device must be compatible with the scanner environment. Visual stimuli can be projected onto a plastic screen inside the scanner bore, and auditory stimuli can be delivered through MR-compatible headphones. In somatosensory experiments, physical touch or vibration on the body surface is required to elicit sensorimotor activations, and multiple stimulators are usually needed in order to stimulate different body parts. Active finger tapping and self-paced movements are commonly used for localizing sensorimotor sites in clinical scans. The timing, intensity, and coverage of manual stimulations generated by the subject or delivered by experimenters are not as consistent and precise as those driven by mechanical devices. However, most vibrotactile devices contain metals or electrical circuits and may not be compatible with the MR environment.

Several MR-compatible devices for somatosensory stimulation have been proposed. Flexible shafts made of carbon fiber have been successfully used to deliver vibrotactile stimuli mechanically in the scanner (Golaszewski et al., 2002a). That device does not use any metallic component inside the scanner, and produces precise vibrating frequencies and amplitudes. Magnetomechanical vibrotactile devices (MVDs) are made of MR-compatible coils, but are sensitive to placement and orientation inside the scanner (Graham et al., 2001). A piezoceramic vibrotactile stimulator generates $1-300 \mathrm{~Hz}$ vibrations, but requires high voltage to produce relatively small displacements (Harrington et al., 2000; Harrington and Downs, 2001; Francis et al., 2000; Gizewski et al., 2005; McGlone et al., 2002). Both magnetomechanical and piezoceramic vibrotactile devices lead electrical wires into the scanner, which may interfere with MR signal acquisition; furthermore, they may be heated by RF pulses if not shielded properly. Similar concerns may exist for experiments that apply electrical stimulation on the skin (Blankenburg et al., 2003; McGlone et al., 2002). Pneumatically driven vibrators and air-puff devices are devoid of electromagnetic interference because they use plastic tubes 
and MR-compatible materials inside the scanner (Briggs et al., 2004; Golaszewski et al., 2002b; Overduin and Servos, 2004; Servos et al., 1998, 1999; Stippich et al., 1999, 2004; Zappe et al., 2004). Pneumatically driven devices usually generate tactile stimulation at lower frequencies $(<150 \mathrm{~Hz})$, which are sufficient for eliciting somatosensory responses. Each of the aforementioned approaches for somatosensory stimulation has advantages and limitations. The selection of devices depends on their applications in various scientific and clinical contexts.

Accurate and detailed somatotopic mapping of the human body surface will improve basic understanding of the somatosensory system, guide neurosurgical planning, and assess plasticity and recovery after brain damage or body injuries (Borsook et al., 1998; Corbetta et al., 2002; Cramer et al., 2000, 2003; Cramer and Bastings, 2000; Cramer and Crafton, 2006; Lee et al., 1998, 1999; Moore et al., 2000b; Ramachandran, 2005; Ramachandran and Rogers-Ramachandran, 2000; Rijntjes et al., 1997). Studies using fMRI have revealed somatotopic representations of the hand, fingers, wrist, elbow, shoulder, foot, toes, lips, and tongue in human brains (Alkadhi et al., 2002; Beisteiner et al., 2001; Blankenburg et al., 2003; Dechent and Frahm, 2003; Francis et al., 2000; Gelnar et al., 1998; Golaszewski et al., 2006; Hanakawa et al., 2005; Hlustik et al., 2001; Kurth et al., 2000; Lotze et al., 2000; McGlone et al., 2002; Miyamoto et al., 2006; Moore et al., 2000a; Overduin and Servos, 2004; Ruben et al., 2001; Servos et al., 1998; Stippich et al., 1999, 2004; van Westen et al., 2004; also see reviews in Burton, 2002). The human face contains important sensory organs and is essential for verbal and nonverbal communications in daily life. However, only a few studies investigated somatotopy of the human face (including the lips and ears) using fMRI (Corbetta et al., 2002; DaSilva et al., 2002; Disbrow et al., 2000; Hodge et al., 1998; Iannetti et al., 2003; Miyamoto et al., 2006; Nihashi et al., 2002; Servos et al., 1999; Stippich et al., 1999) and other non-invasive and invasive techniques (Nakamura et al., 1998; Nevalainen et al., 2006; Nguyen et al., 2004, 2005; Sato et al., 2002, 2005; Schwartz et al., 2004; Yang et al., 1993). In most studies, only two or three locations on the face were stimulated manually or automatically. Somatotopic mapping of the whole face using fMRI is challenging because of the difficulty in delivering tactile stimuli to the face surrounded by a head coil. Most of the aforementioned MRcompatible devices have been used mainly for stimulation on the fingers. For instance, MVDs (Graham et al., 2001) were not tested for face stimulation inside the head coil. In addition, multiple stimulators are required to cover the whole face during the same scanning session. The arrangement and fixation of multiple stimulators with respect to the face inside the head coil remain a challenging task.

In this study, a computer-controlled MR-compatible pneumatic system (Dodecapus) was constructed and used to automatically and systematically deliver somatosensory stimuli around the whole face inside the head coil. Block-design and phase-encoded paradigms were used to map the locations and internal organization of face representation in motor, parietal, and primary and secondary somatosensory cortices. The phase-encoded technique has been successfully employed in retinotopic, tonotopic, spatiotopic, and somatotopic mapping experiments (Engel et al., 1994; Overduin and Servos, 2004; Sereno et al., 1995, 2001; Servos et al., 1998, 1999; Talavage et al., 2004). In a different session, the same system and paradigms as in the face somatotopy experiment were used to map the lip and finger representations.

\section{Materials and methods}

\section{Participants}

Six healthy right-handed subjects ( 2 males, 4 females; aged 20 30) participated in this study. All subjects participated in one fMRI session for face mapping, and four of them participated in one additional session for lip and finger mapping. Subjects gave informed consent, according to protocols approved by the Human Research Protections Program of the University of California, San Diego.

\section{System design and setup}

The Dodecapus system is composed of the following components (Fig. 1): a portable stimulus computer (XPC, Shuttle Inc., Taiwan), a portable air compressor (Model No. Y1000; Husky Professional Tools, Atlanta, GA), a pneumatic control module (indicated by a darkened box in Fig. 1), a power supply (Model No. APS60ES-13; Advanced Power Solutions, Pleasanton, CA) for the pneumatic control module, a 12-channel MR-compatible manifold for face and lip stimulation (Fig. 2), and two dozens of 25 -ft 1/4-in. plastic tubes. The pneumatic control module includes control circuits (designed and implemented by R.-S.H. for this project) and solenoid air valves ("S" Series Valve; Numatics Inc., Highland, MI). The control circuits decode eight-bit TransistorTransistor Logic (TTL) pulses (binary codes) sent from a computer parallel port and activate one of 12 control lines connected to the solenoid air valves. All metallic and electronic components in Fig. 1 stay in the scanner control room, and only the plastic tubes and the manifold enter the scanner room.

The manifold includes two polyvinyl chloride (PVC) blocks and 12 adjustable plastic gooseneck legs ending in nozzles. The manifold is mounted on a rail at the top of a GE (or Siemens) 8channel head coil (Fig. 2). The rail was originally designed to support a mirror for visual stimuli presentation. Each leg of the manifold is composed of 20-22 segments, a 1/16-in. round nozzle, and a fitting (Loc-Line Inc., Lake Oswego, OR) rooted to the rigid PVC base. These gooseneck segments can be assembled into any desired length with special pliers (Loc-Line). The connection between segments is tight enough to hold its position while still allowing the whole leg to be freely bent to aim it at different locations on the face and lips (Fig. 2) or neck and shoulders. Another set of a dozen tubes was used to deliver air puffs to the tips of 10 fingers and the palms (Fig. 2A). Twenty-four air tubes were led through waveguides on the radio frequency (RF) shielding wall and 12 of them at a time were connected to the solenoid air valves in the scanner control room. These tubes can be connected or disconnected easily so that the experimenter can alternate between face-only, lips-only, face vs. lips, fingers-only, face vs. fingers, and lips vs. fingers paradigms during the same scanning session.

The pneumatic control module is controlled by TTL pulses sent from a parallel port of the portable computer (XPC) running the Linux operating system. Programs written in $\mathrm{C} / \mathrm{C}++$ with the OpenGL libraries (Silicon Graphics Inc., Mountain View, CA) enable control of visual, auditory, and somatosensory stimuli with millisecond precision from the same computer. Visual stimuli were back-projected onto a direct-view screen attached to the ceiling inside the scanner bore. The subject's head was tilted forward so that they could view the screen directly without a mirror. This setup 


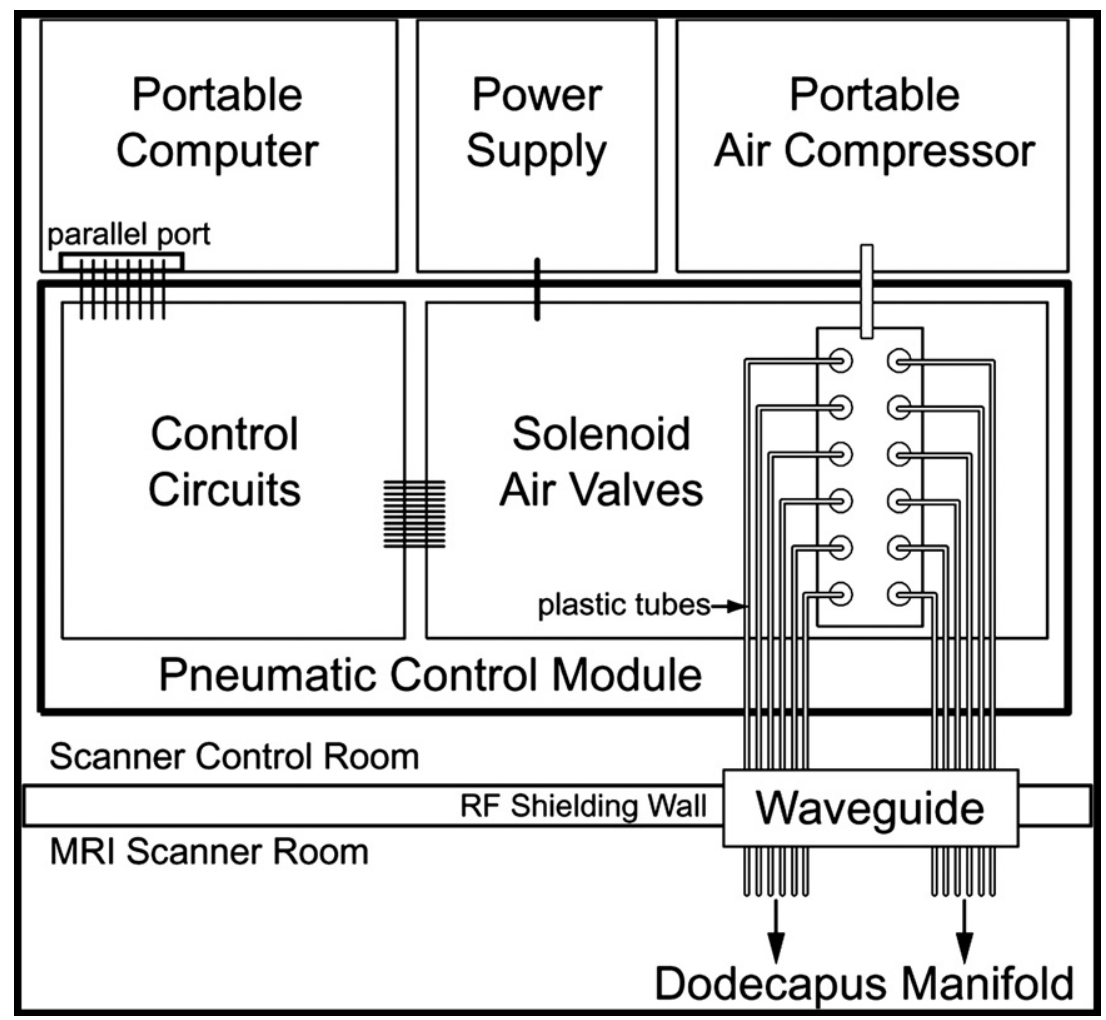

Fig. 1. Spatial layout of Dodecapus stimulus generation components in the scanner control room. The sizes of components are not drawn to scale. The control circuits are connected to the parallel port of the portable computer via eight signal lines. Twelve control lines are connected between the control circuits and the solenoid air valves. The waveguide provides a conduit through the radio frequency (RF) shielding wall to the scanner room for the plastic tubes, which are connected to the Dodecapus manifold inside the scanner bore.

allows us to present aligned air puffs and visual stimuli at the same polar angle with respect to the face (Sereno and Huang, 2006). The solenoid air valves ( $5 \mathrm{~ms}$ response time) receive airflow from the portable air compressor located in the scanner control room (Fig. 1). The input air pressure (30-40 psi) was adjusted so that a $500 \mathrm{~ms}$ air puff could be reliably detected by the subject as a light touch. Only one valve is opened at a time in order to ensure that all air puffs have the same pressure. Each flash of a light emitting diode (LED) on the pneumatic control module signals an opening of an air valve, which helps with monitoring of the stimuli.

Subjects were posed in the scanner with their heads tilted slightly forward (Fig. 2). The tilt also created enough room for the adjustable plastic nozzles around the face (note the lower part of the face was outside the head coil). The air puffs were perceived as light, slightly cool touches to a localized region of the face. The air compressor was located in the scanner control room and generates air puffs that were very close to the room temperature (about $70-75{ }^{\circ} \mathrm{F}$ with airconditioning). The feeling of slight coolness was likely due to the simple fact of airflow and evaporative cooling. The goal of our paradigm is to find somatotopic maps of the body surface. Given that there was no difference in the temperature of the air puffs delivered to each of 12 locations on the skin, it is unlikely that temperature could generate a systematic error or a periodic signal. A bite bar was not used so that there was enough space around the face for the plastic nozzles and to minimize stimulation of the teeth and lips. Instead, foam padding was inserted in the head coil to minimize head movement. To completely mask the sound of the air puffs, subjects listened (through ear plugs) to white noise delivered by MR-compatible headphones.
Subjects were instructed to close their eyes and mouth and the scanner room was completely darkened during the experiment.

\section{Experimental paradigms}

\section{Block-design localizers}

Three block-design paradigms were employed to localize the cortical representations of the face, lips and fingers. Each twocondition scan consisted of eight cycles of 32-s block pairs. In the first "Face Localizer" paradigm, trains of 100-ms air puffs were delivered randomly to 12 locations on the face (Fig. 2A) for $16 \mathrm{~s}$ (ON-block), followed by $16 \mathrm{~s}$ of no stimulation (OFF-block). There was no delay between the end of one air puff and the start of the next at a different location. The second "Lip Localizer" paradigm was identical to the "Face Localizer" except that all nozzles were aimed around the lips (Fig. 2B). In the third "Finger Localizer" paradigm, the 16-s ON-block consisted of trains of 100-ms air puffs delivered to the fingertips and the palm near the base of the thumb (P1) on both hands. Each new air puff was delivered to a randomly selected location with no delay between the end of one air puff and the start of the next. There were no stimuli during the 16-s OFF-blocks. One additional block-design paradigm, "Face vs. Fingers", was employed to identify the borders between face and finger representations. In this paradigm, trains of 100-ms air puffs were delivered randomly to six locations on the right half of the face for $16 \mathrm{~s}$, followed by $16 \mathrm{~s}$ of random stimulation to the right fingertips (D1-D5) and the right palm (P1). This "A vs. B" paradigm also demonstrates the flexible use of the Dodecapus system for stimulating different body parts during the same scan. 

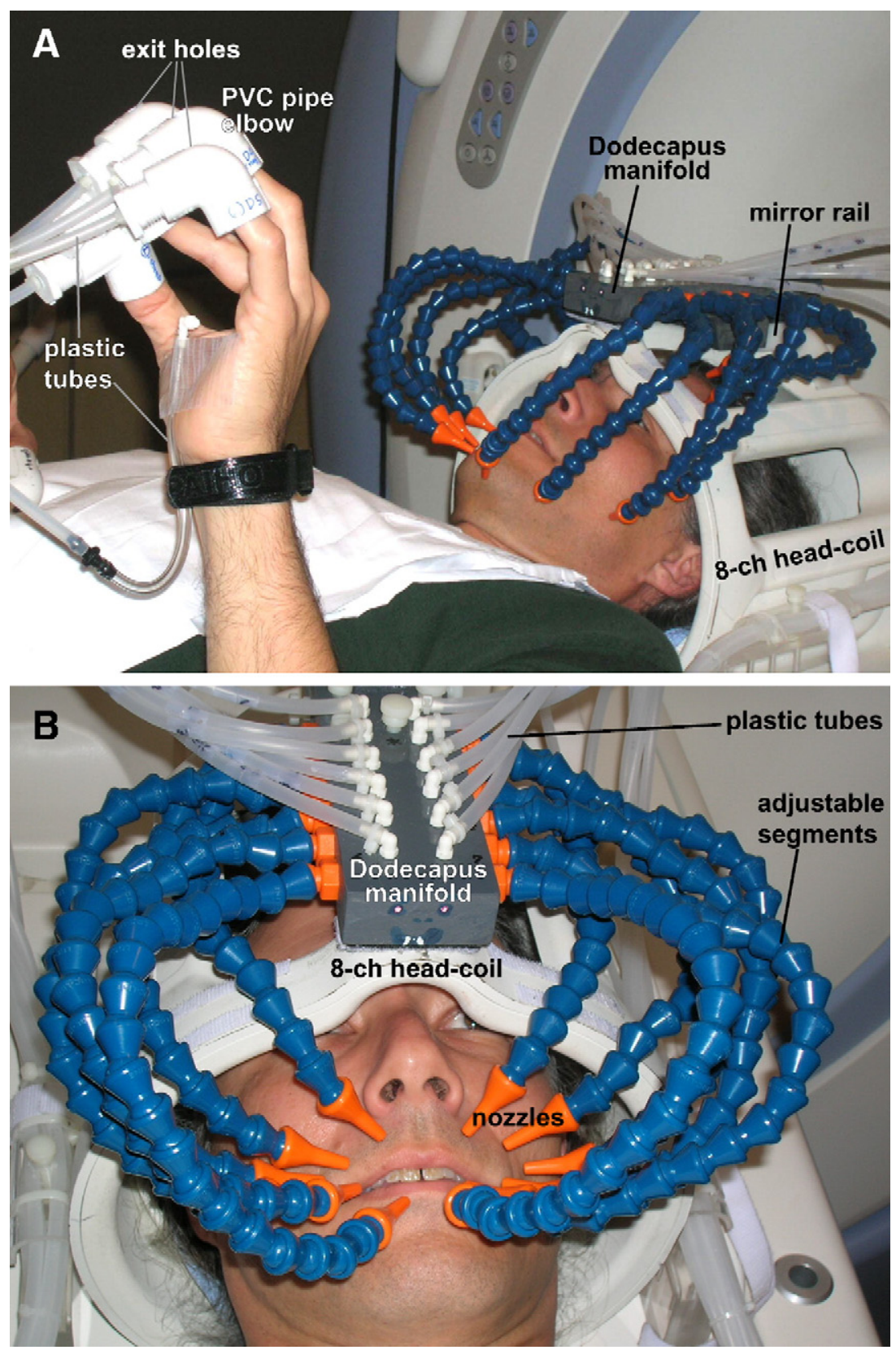

Fig. 2. Demonstration of experimental setups. (A) Face and fingertip/palm stimulation. (B) Air puff nozzles around the lips. The manifold is mounted on top of the 8-channel head coil by sliding its base into the mirror rail. Each adjustable "leg" is connected to a 25 -ft plastic tube via an elbow connector on top of the manifold. During the actual experiment, subjects rested their hands on their abdomen, and wore earplugs and headphones. Note that an exit hole was drilled on the external corner of each PVC pipe elbow to provide an outlet for the airflow, which ensured that only the fingertips were stimulated. Subjects closed their mouth and eyes, and wore earplugs and headphones during the experiment.

\section{Phase-encoded somatotopy}

Three phase-encoded paradigms were employed to map the detailed somatotopy within each area localized in the blockdesign paradigms. Each scan consisted of eight cycles of 64-s periods. In the first paradigm, trains of $100-\mathrm{ms}$ air puffs were sequentially delivered to each of 12 evenly spaced locations on the face in a clockwise or counterclockwise direction during a 64-s period (Fig. 2A). The air puff stimulation always started at the upper midline of the forehead, swept down to the lower midline of the chin, then continued up the opposite side of the face. This arrangement ensured that contralateral and ipsilateral hemispheres were activated during the first and second halfcycle, respectively. $80 \%$ of the gaps between the end of the previous air puff and the beginning of the next air puff were $100 \mathrm{~ms}$, and $20 \%$ of the gaps were $200 \mathrm{~ms}$. Subjects were asked to passively monitor for irregularities in the air puff patterns. Subjects merely noted to themselves when longer gaps (200 ms) occurred and made no overt response. All subjects participated in four "Phase-encoded" face mapping scans (two in each direction) following a "Face Localizer" scan. In the second paradigm, the 
plastic legs were adjusted and aimed at 12 evenly spaced locations around the upper and lower lips (Fig. 2B). In the third paradigm, trains of 100-ms air puffs were sequentially delivered to the fingertips (D1-D5) and palms (P1) near the base of the thumbs during a 64-s period in the following order: right $\mathrm{P} 1 \rightarrow$ right $\quad \mathrm{D} 1 \rightarrow$ right $\quad \mathrm{D} 2 \rightarrow$ right $\quad \mathrm{D} 3 \rightarrow$ right $\quad \mathrm{D} 4 \rightarrow$ right $\mathrm{D} 5 \rightarrow$ left D5 $\rightarrow$ left D $\rightarrow$ left D3 $\rightarrow$ left D2 $\rightarrow$ left D1 $\rightarrow$ left P1.
The temporal patterns of air puffs were identical in all three phase-encoded paradigms.

Image acquisition

Each experimental session consists of 5 or 6 functional scans and one structural scan. Echo-planar images (EPI) were collected
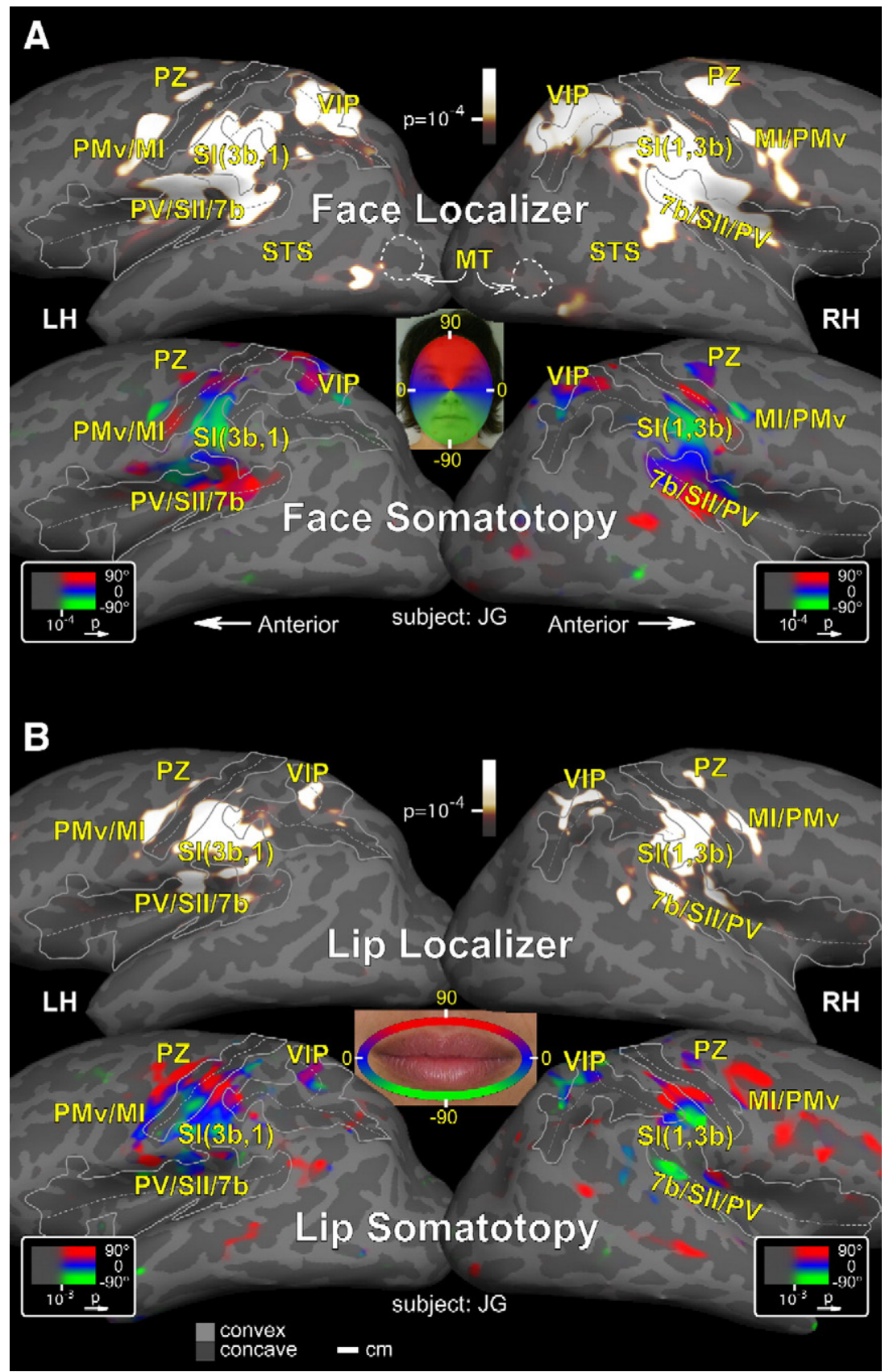

Fig. 3. Face and lip somatotopy of a single subject (JG). (A) Face maps. (B) Lip maps. Somatotopic maps of face or lips were rendered on inflated cortical surfaces (lateral view) for "Localizer" (top) and "Phase-encoded Somatotopy" (bottom) scans, respectively. Regions activated during ON-block in "Localizer" scans were rendered with heat scales (white). Three main clusters of somatosensory areas were activated: primary areas $(3 \mathrm{~b}, 1,2)$, secondary areas (PV, SIIproper, 7b), and parietal areas (VIP and AIP) (see text for other areas). Polar angles of contralateral face and lip somatotopy were color-coded: $90^{\circ}$ (red) $\rightarrow 0^{\circ}$ (blue) $\rightarrow-90^{\circ}$ (green). The insets show the significance thresholds. Sulci (concave) and gyri (convex) are indicated by dark and light gray shading, respectively. Gray solid contours indicated the outlines of the central, postcentral, intraparietal, and Sylvian sulci. Gray dashed contours indicate fundi. White dashed contour represents the boundary of area MT as determined in retinotopic mapping experiments from the same subject. STS: superior temporal sulcus; LH: left hemisphere; RH: right hemisphere. 
during 256-s or 512-s functional scans (GE 3 T Signa Excite, 8-channel head coil, single shot EPI, FOV $=20 \mathrm{~cm}, 3.125 \times$ $3.125 \mathrm{~mm}$ in-plane, $3-4 \mathrm{~mm}$ thick slices, 128 or 256 images per slice, 31 axial slices, $64 \times 64$ matrix, flip angle $=90^{\circ}, \mathrm{TE}=30 \mathrm{~ms}$, $\mathrm{TR}=2000 \mathrm{~ms}$ ). Since the subject's head was slightly tilted forward, this image prescription typically included the whole cerebral cortex without using oblique slices. Structural images (FSPGR, FOV $=25 \mathrm{~cm}, 1 \times 1 \mathrm{~mm}$ in-plane, $1.3 \mathrm{~mm}$ thick slices, 106 axial slices, $256 \times 256$ matrix) were collected at the same plane as the functional scans.

\section{Data analysis}

Data were analyzed using surface-based Fourier methods (Sereno et al., 1995, 2001). Functional scans were motioncorrected using AFNI 3dvolreg (Cox, 1996; http://afni.nimh.nih. gov/afni). FreeSurfer (Dale et al., 1999; Fischl et al., 1999) was used to reconstruct the cortical surface for each person from a pair of structural scans (FSPGR, $1 \times 1 \times 1 \mathrm{~mm}$ ) taken in a separate session. The last scan of each functional session was an alignment scan (FSPGR, $1 \times 1 \times 1.3 \mathrm{~mm}$ ) used to establish an initial surface

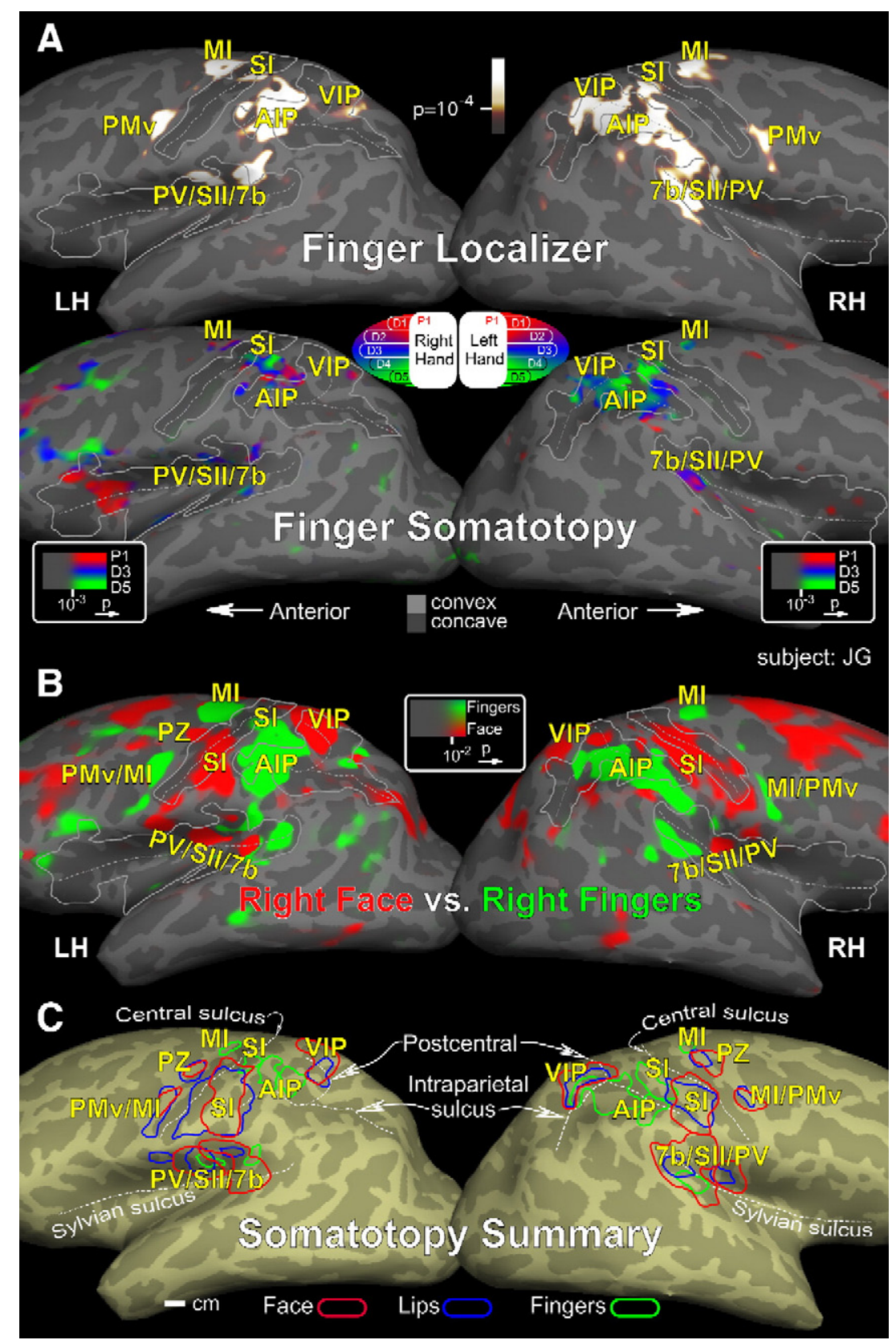

Fig. 4. Finger somatotopy and summary of same subject (JG). (A) Finger maps. (B) Face vs. finger representations. (C) Summary of somatotopy. Somatotopic maps of fingers were rendered on inflated cortical surfaces (lateral view) for "Localizer" (top) and "Phase-encoded Somatotopy" (bottom) scans, respectively. Regions activated during ON-block in "Localizer" scans were rendered with heat scales (white). Contralateral somatotopy of fingers and palms was color-coded: $\mathrm{P} 1$ (red) $\rightarrow \mathrm{D} 1 \rightarrow \mathrm{D} 2 \rightarrow \mathrm{D} 3$ (blue) $\rightarrow \mathrm{D} 4 \rightarrow \mathrm{D} 5$ (green). In panel B, regions activated during "right face versus right fingers" stimulation were rendered in red and green, respectively. Other conventions follow Fig. 3. 
Table 1

Locations (center of mass) of somatosensory representations activated in the localizer scans from a single subject (JG)

\begin{tabular}{|c|c|c|c|c|c|c|c|}
\hline \multirow[t]{3}{*}{ Areas } & \multirow{3}{*}{$\begin{array}{l}\text { Body } \\
\text { parts }\end{array}$} & \multicolumn{3}{|c|}{ Left hemisphere } & \multicolumn{3}{|c|}{ Right hemisphere } \\
\hline & & \multicolumn{3}{|c|}{ Talairach coordinates } & \multicolumn{3}{|c|}{ Talairach coordinates } \\
\hline & & $x$ & $y$ & $z$ & $x$ & $y$ & $z$ \\
\hline \multirow[t]{3}{*}{ SI } & Face & -50 & -15 & 42 & 51 & -9 & 40 \\
\hline & Lips & -50 & -13 & 44 & 54 & -10 & 35 \\
\hline & Fingers & -35 & -26 & 55 & 47 & -30 & 62 \\
\hline \multirow[t]{3}{*}{$\mathrm{SII} / \mathrm{PV}$} & Face & -47 & -15 & 19 & 38 & -14 & 23 \\
\hline & Lips & -47 & -17 & 17 & 44 & -16 & 20 \\
\hline & Fingers & -45 & -21 & 20 & 50 & -18 & 23 \\
\hline \multirow[t]{3}{*}{$7 b$} & Face & -45 & -40 & 15 & 47 & -34 & 23 \\
\hline & Lips & -41 & -37 & 10 & 53 & -30 & 23 \\
\hline & Fingers & -53 & -28 & 17 & 51 & -30 & 23 \\
\hline \multirow[t]{2}{*}{$\mathrm{MI} / \mathrm{PMv}$} & Face & -48 & -2 & 37 & 51 & 4 & 44 \\
\hline & Lips & -54 & -2 & 37 & 51 & 4 & 42 \\
\hline MI & Fingers & -31 & -11 & 59 & 39 & -19 & 64 \\
\hline PMv & Fingers & -52 & -2 & 35 & 58 & 8 & 32 \\
\hline \multirow[t]{2}{*}{ VIP } & Face & -26 & -41 & 51 & 31 & -51 & 59 \\
\hline & Lips & -26 & -43 & 47 & 35 & -53 & 62 \\
\hline AIP & Fingers & -42 & -34 & 44 & 44 & -34 & 51 \\
\hline PZ & Face & -43 & -7 & 55 & 41 & -8 & 60 \\
\hline
\end{tabular}

registration, which was then refined using manual blink comparison with the structural images to achieve an exact overlay. A Fourier transform was computed for the time series at each voxel after removing the linear trend. An F-ratio was constructed by comparing the power at the stimulus frequency ( 8 or 16 cycles per scan) to the power of the noise (other frequencies) and converted to a (uncorrected) $p$-value by considering the degrees of freedom of signal and noise. In block-design experiments, the phase angle at the stimulus frequency was divided into two bins corresponding to $\mathrm{ON}$ and OFF block activations (ON phases were displayed using a heat scale ending in white; OFF-block responses were negligible). In phase-encoded mapping experiments, the phase angle was displayed using a continuous color scale (red $\rightarrow$ blue $\rightarrow$ green). In both cases, the saturation of the colors was modulated by the $p$-value (after passing it through a sigmoid), as illustrated in the color bar insets in the figures, effectively thresholding the data. The software used can be downloaded from http://surfer.nmr.mgh. harvard.edu/download.html. A download containing retinotopy analysis tools is available at http://kamares.ucsd.edu/ sereno/ csurf/tarballs/.

\section{Results}

Results of functional scans were rendered on inflated cortical surfaces using FreeSurfer (Dale et al., 1999; Fischl et al., 1999; Sereno et al., 1995, 2001). Figs. 3 and 4 illustrate somatotopic representations of the face, lips, and fingers of the same subject (JG). Fig. 4C shows a summary of somatotopic areas in this subject with outlines derived from the phase-encoded mapping scans (Figs. 3 and 4A). Table 1 summarizes the Talairach coordinates of multiple somatotopic areas activated in the localizer scans from this subject. Figs. 5 and 6 show results from four additional subjects.

\section{Face representations}

A 256-s "Face Localizer" scan revealed multiple areas containing contralateral and ipsilateral representations of the face (Figs. 3A and 5), including primary somatosensory (SI) cortex at the inferior postcentral gyrus, parietal ventral area $(\mathrm{PV})$ and secondary somatosensory cortex (SII) at the upper bank of Sylvian sulcus, area $7 \mathrm{~b}$ at the posterior end of the Sylvian sulcus, primary motor cortex (MI) and premotor ventral (PMv) on the inferior precentral gyrus (Preuss et al., 1996; Stepniewska et al., 1993), a polysensory zone (PZ) at the superior precentral gyrus (Graziano and Gandhi, 2000), the ventral intraparietal area (VIP) at the confluence of the intraparietal sulcus and the postcentral sulcus, and a small area anterior to the middle temporal (MT) area.

An average of four 512-s phase-encoded scans (a vector average of two clockwise and two counter-clockwise scans after reversing the phase of one set to cancel static delay differences) further revealed continuous somatotopic organization of the contralateral face (Figs. 3A and 5) within each area activated in the "Face Localizer" scan. In the primary somatosensory cortex (SI), the contralateral face is organized upright along the postcentral gyrus. The contralateral forehead representation (red) extends into the central sulcus, and cheek and chin (green) are located at the inferior postcentral gyrus. The face representation in area $7 \mathrm{~b}$ in the posterior Sylvian sulcus is upside down. In some subjects, the lower face representation of $7 \mathrm{~b}$ joins the lower face representation of SI (this is a so-called "congruent border", which is often seen with visual maps: e.g., horizontal meridian area $1 \rightarrow$ lower vertical meridian area $1 \rightarrow$ lower vertical meridian area $2 \rightarrow$ lower vertical meridian area 2 ). The representation of the contralateral face in secondary somatosensory cortex (SII) on the upper bank of the Sylvian sulcus is also upside down. A region at the intersection of the postcentral sulcus and intraparietal sulcus (VIP) has yet another contralateral face representation, where the upper parts of the face are represented anterior to the lower parts of the face (Huang and Sereno, 2005; Sereno and Huang, 2006). Some subjects (JG in Fig. 3A; EG in Fig. 5B) also showed contralateral somatotopic organization anterior to the central sulcus in the polysensory zone (PZ) and primary motor cortex (MI).

\section{Upper and lower lip representations}

A 256-s "Lip Localizer" scan revealed multiple contralateral and ipsilateral representations of upper and lower lips (Figs. 3B and 6), including primary somatosensory (SI) cortex on the inferior postcentral gyrus, parietal ventral area (PV) and secondary somatosensory cortex (SII) at the upper bank of Sylvian sulcus, area $7 \mathrm{~b}$ in the posterior Sylvian sulcus, primary motor cortex (MI) on the inferior precentral gyrus, polysensory zone (PZ) at the superior precentral gyrus, postcentral sulcus, and ventral intraparietal area (VIP). All lip areas except the one in SI are smaller than their adjacent face areas identified by the "Face Localizer" scan.

Fig. 5. Face somatotopy for four additional subjects. (A) Subject YT. (B) Subject EG. (C) Subject YW. (D) Subject MD. Similar clusters of face representations were activated. Note that activations found in primary and secondary auditory cortex (AI/AII) in panel D were likely due to poor masking of air puff noise (masked well in all other experiments). All conventions follow Fig. 3A. 

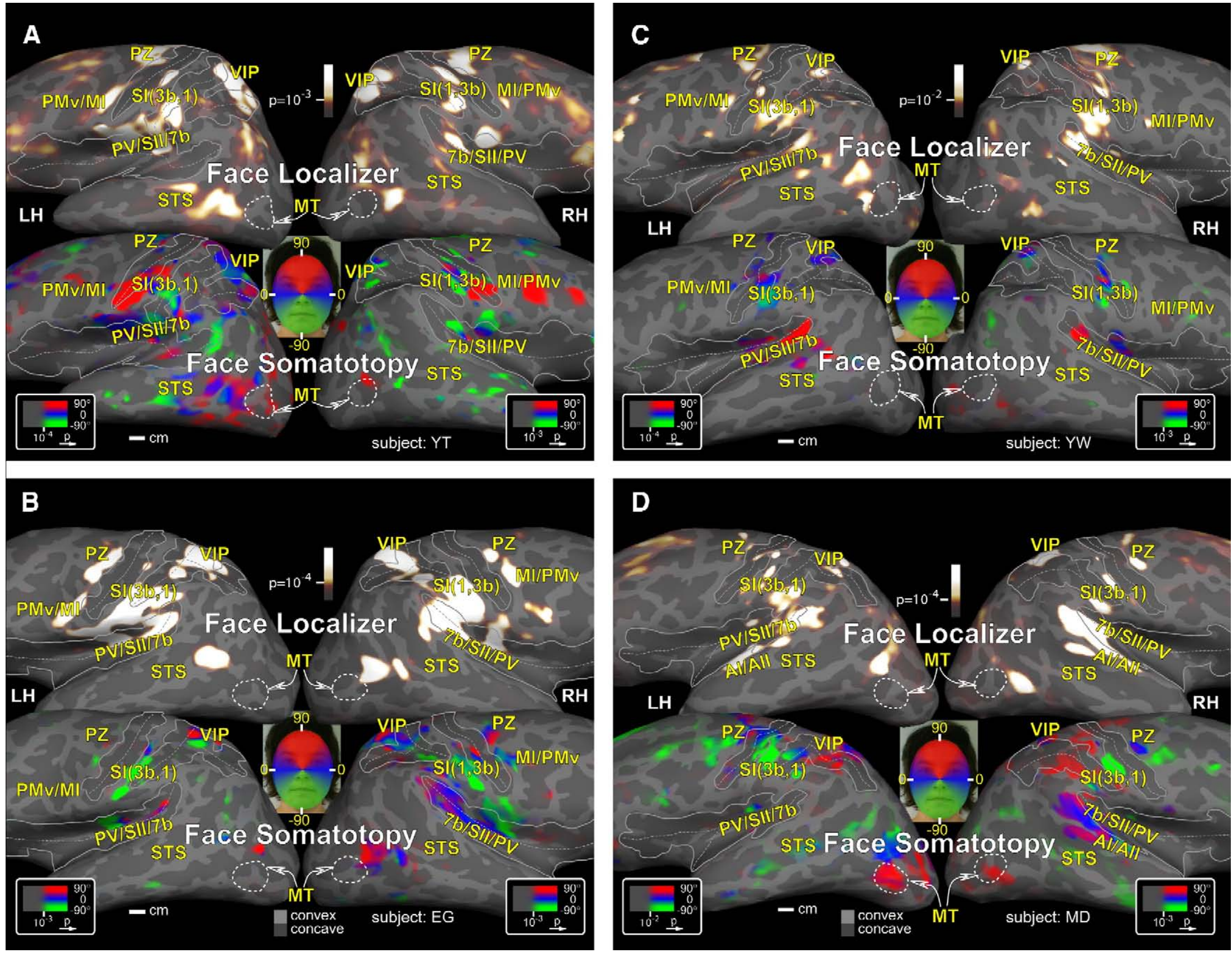

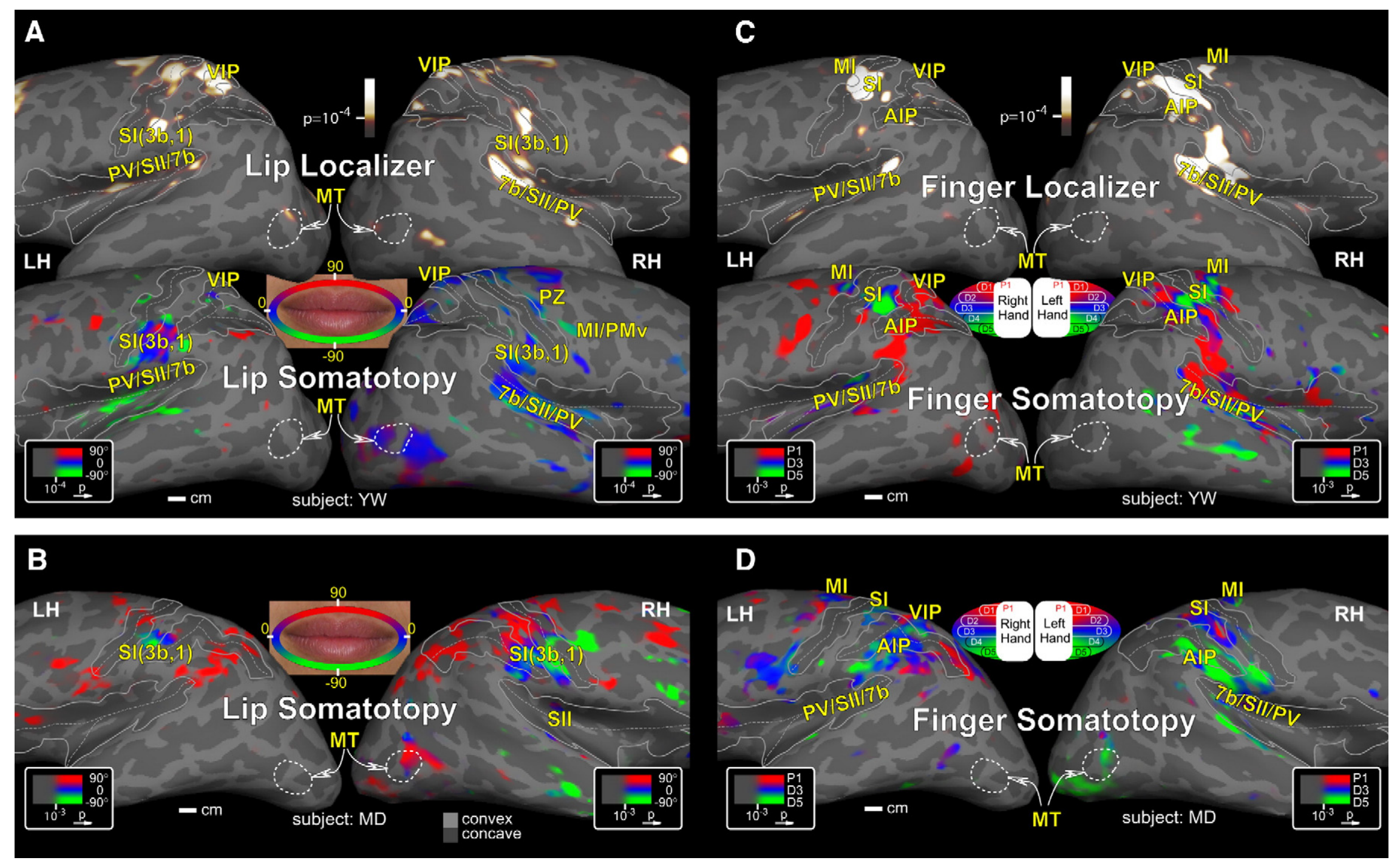

Fig. 6. Lip and finger somatotopy for the fourth and fifth subjects. (A, C) Subject YW. (B, D) Subject MD. Phase-encoded mapping showed somatotopy within the primary and secondary clusters. Note the extensive passive finger somatotopy in area AIP in the left hemisphere of subject MD (D), which closely resembles activations seen in the first subject (Fig. 4A). All conventions follow Figs. 3B and 4A. 
A 512-s phase-encoded scan further revealed the somatotopic organization (Figs. 3B and 6) within each patch activated in the "Lip Localizer" scan. In the primary somatosensory cortex (SI), the contralateral lips are organized upright along the postcentral gyrus. The contralateral upper-lip representation (red) extends into the central sulcus, and the lower-lip representation (green) is located on the inferior postcentral gyrus. The upper and lower lip representations in the secondary somatosensory cortex (SII) are small and do not have a full sweep of phases. This may reflect the lack of a full contralateral representation, or it may simply be due to the fact that the internal details of the representation are too small to be resolved by our imaging resolution (whose minimum voxel size is limited by signal-to-noise considerations). The left primary motor cortex, however, shows a complete representation of the contralateral lips. The large size of the upper and lower lip representations in most somatosensory areas (Figs. 3B and 6) suggests that the lips (mouth) could be thought to be the "fovea" of the face. Note, however, that in VIP, the lip representation appears to be smaller than the periphery of the face representation.

\section{Digit representations}

A 256-s "Finger Localizer" scan revealed multiple areas of the contralateral and ipsilateral representations of fingers (Figs. 4A and 6 ), including primary somatosensory (SI) cortex on the superior postcentral gyrus, secondary somatosensory cortex (SII) on the upper bank of Sylvian sulcus, area $7 \mathrm{~b}$ at the posterior end of the Sylvian sulcus, primary motor cortex (MI) at the superior precentral gyrus, and areas in the anterior and ventral intraparietal sulcus (AIP and VIP).

A 512-s phase-encoded scan revealed some of the details of the somatotopic organization within the regions (Figs. 4A and 6) activated in the "Finger Localizer" scan. In the primary somatosensory cortex (SI), a complex pattern of activation was revealed, with clear evidence for multiple representations of each digit. Even more than in the case of the lips, the individual finger representations are right at the limit of our spatial resolution. To completely resolve the somatotopic representation of the digits, it is likely that a higher signal-to-noise surface coil is required in order to acquire high-resolution images with smaller voxels.

Interestingly, a substantial degree of digit somatotopy was revealed just inferior to VIP at the confluence of the postcentral and intraparietal sulci in a region given several different labels, including AIP in this paper (see Discussion). The overall positioning of face and forelimb in VIP and this more inferior region (face medial, forelimb lateral) are opposite to that in the somatomotor strip (face lateral, forelimb medial).

\section{Face vs. fingers}

A 256-s "Face vs. Fingers" scan was designed to identify the overall borders between cortical representations of the face and fingers. Because only areas on half of the body surface (right face and right fingers) were stimulated, this scan revealed both contralateral and ipsilateral representations of the face and fingers (Fig. 4B). Contralateral to the stimulation, three main postcentral finger representations were found: SI (areas 3b, 1, 2), SII (areas PV, SII proper, and $7 \mathrm{~b}$ ), and AIP (adjacent to SI); as well as precentral finger representations: MI and PMv. Face representations were also found at three postcentral regions: SI (areas 3b, 1, 2), SII (areas PV, SII proper, and $7 b$ ), and VIP. The activated focus on the precentral gyrus was tentatively labeled PZ (as opposed to the face representation in MI or PMv). Note that the face region revealed by the "Face vs. Fingers" comparison was smaller than the face region revealed by the "Face Localizer" scan; in particular, the lateral part of AIP defined as a face representation by "Face vs. Fingers" was also activated by the "Face Localizer" comparison (face vs. nothing).

The representations of the face and fingers in the left (contralateral) hemisphere generally agreed with the areas found in the "Localizer" scans. However, the right hemisphere ipsilateral to all stimulation - also showed areas that preferred face versus fingers stimulation. The regions preferring each type of stimulation in the ipsilateral hemisphere were in similar (homotopic) positions to areas in the contralateral hemisphere.

\section{Discussion}

Functional magnetic resonance imaging has become a routine tool in cognitive neuroscience but is currently less used for clinical studies. Experimental setup in the MR environment remains a challenging task, especially for somatosensory experiments. In this study, a computer-controlled, MR-compatible system was constructed and demonstrated that can deliver air puff tactile stimuli automatically inside or near the RF head coil in the scanner bore.

Fully automatic tactile stimulation could potentially be useful for clinical situations where the patient cannot follow verbal instructions and actively generate motor responses. Self-paced stimulation-such as the venerable "finger-tapping" paradigm commonly used to localize hand somatomotor cortex-can be difficult to accurately control, even for a healthy volunteer. These problems are greatly magnified when one considers self-stimulation of the face. In our pilot experiments, the subject gently touched different part of his face with a brush while listening to verbal instructions through headphones in the head coil (Sereno and Huang, unpublished data). This experiment resulted in massive head-motion artifacts correlated with the experimental paradigm. An additional complication of self-stimulation is that brain activities elicited by active hand movements may not be distinguished from those elicited by passive tactile stimulation. These problems may be minimized if the stimuli are delivered by a well-trained experimenter (Iannetti et al., 2003; Miyamoto et al., 2006). However, this approach is practically limited to blockdesign paradigms (ON vs. OFF) on one or two sites during each scan. Precise manual stimulation over a large continuous body surface may be difficult. These issues make fully automatic and passive tactile stimulation a preferable solution.

The Dodecapus system can be flexibly and rapidly adapted to stimulation of the face, lips, fingers, as well as other body parts. This flexibility is important given the extremely complex shape of the somatosensory receptor surface. The pulse sequence of air puffs of each channel is completely programmable such that one can implement experimental paradigms with various temporal and spatial patterns of air-puff patterns, e.g., stimulation on the left face vs. right face. Although the current prototype has only 12 air-puff channels, it is easily expandable by adding more solenoid air valves and "legs" to it (Briggs et al., 2004; Zappe et al., 2004). The PC parallel port interface ( 8 bits) can control up to 256 channels. One limitation of pneumatically driven systems is that they generate stimulation at lower frequencies than vibration-based systems. Dodecapus was designed to deliver low frequency air puffs $(\sim 10 \mathrm{~Hz})$ for somatotopic mapping experiments. However, 
one can replace the nozzle of the plastic leg with various heads or vibrators that generate high-frequency vibrations (Gelnar et al., 1998). The adjustable plastic legs of Dodecapus made it easy to precisely direct nozzles to any location on the face from various angles, which may be useful for trigeminal pain research (Borsook et al., 2004; DaSilva et al., 2002; Iannetti et al., 2003). For example, one can aim at all three trigeminal branches (V1-V3) on both sides of the face with 12 air puff legs. In addition, a plunger with a probe could be added to the end of each flexible tube. There is sufficient air pressure to drive the probe with enough force to generate a range of sensations from light touches to noxious stimulation. Finally, the air delivered through the flexible legs could be heated or cooled to measure sensitivity to temperature.

This study is a first step toward a complete non-invasive mapping of the human somatosensory cortical representation. We interpret our results first in light of previous, high-resolution microelectrode mapping of somatosensory cortex non-human primates. Merzenich et al. (1978) initially found that the area previously identified as SI actually contained four separate representations of the body: area $3 \mathrm{a}$ at the fundus of the central sulcus (responding mainly to muscle receptors), and three areas responding to light touch: areas $3 \mathrm{~b}$ and 1 containing the smallest receptive fields, and area 2 containing somewhat larger receptive fields. Other work (Coq et al., 2004; Disbrow et al., 2000; Krubitzer et al., 1995; Wu and Kaas, 2003) showed that the region originally identified as SII in the Sylvian sulcus actually consisted two separate areas, SII proper and the parietal ventral somatosensory area (PV); this pattern was common to virtually all mammals. The multiple subdivisions of SI seen in monkeys, by contrast, are not common to all mammals (Kaas et al., 1979, 2002). Just posterior to SII proper is yet another representation, area $7 \mathrm{~b}$ (Friedman et al., 1980), which spills out of the posterior end of the Sylvian sulcus. Finally, it was known that neurons in the ventral intraparietal sulcus (VIP) have localized receptive fields on the face (Duhamel et al., 1998); but these neurons were not thought to be arranged into a topographic map (Huang and Sereno, 2005; Sereno and Huang, 2006).

Our fMRI results provide evidence for somatotopic maps in all of the aforementioned areas in the somatosensory cortex, as well as areas VIP and AIP in the parietal cortex. Before comparing our results with microelectrode mapping experiments, it is important to consider the different strengths of the two methods. Microelectrode mapping has better resolution than fMRI, but it is more difficult to sample the cortex evenly with an electrode (Jain et al., 2001; Hayashi et al., 1999; Manger et al., 1996, 1997). By contrast, fMRI sampling is uniform but coarser, which runs the risk of missing or blurring maps whose dimensions are close to voxel sizes.

In SI (defined as 3a, 3b, 1, and 2), in most cases, we found evidence for multiple representations of the contralateral face, lips, and fingers. Given the gentleness of our stimuli, we did not expect to activate area $3 \mathrm{a}$. However, in most cases we were not able to positively distinguish the representations in $3 \mathrm{~b}, 1$, and 2 . An additional difficulty in distinguishing these areas is that we only mapped one coordinate of the two-dimensional somatosensory maps (face polar angle but not face 'eccentricity' [radial distance from the mouth]; digit numbers but not distance from the base of the finger). This will have to wait for the construction of a stimulation device with a higher nozzle count (Zappe et al., 2004) combined with higher resolution scans using a surface coil. Nevertheless, the repeated representation of particular face locations, lip locations, and finger locations in virtually every scan strongly suggests that there are multiple representations of the face, lips, and fingers in human SI (see also Blankenburg et al., 2003; Moore et al., 2000a; Kurth et al., 2000; Overduin and Servos, 2004; van Westen et al., 2004).

We also found evidence for multiple representations of the body in the Sylvian sulcus in the regions expected to be occupied by PV, SII proper, and area $7 \mathrm{~b}$. The strongest evidence for three representations in this region is seen in Fig. 4B, left (contralateral) hemisphere, where three face and three finger representations are clearly visible in the Sylvian sulcus.

The face localizer scan activated several areas anterior to MT (as defined in these subjects by retinotopic mapping; data not shown), which have been previously reported for moving tactile stimuli on the hand (Hagen et al., 2002; Blake et al., 2004; Beauchamp, 2005). The activated region was somewhat variable across subjects (Figs. 3A and 5). In most cases, the activated region adjoined MT but in a few instances, the activated region was found near the STS.

Finally, we corroborated our finding of face somatotopy in area VIP (Huang and Sereno, 2005; Sereno and Huang, 2006). Additionally, we found evidence for a small representation of the lips in area VIP. Immediately adjacent to VIP, we found strong evidence for passive finger somatotopy in an area just inferior to the confluence of postcentral and intraparietal sulci. This area has been labeled PP (posterior parietal) by Ruben et al. (2001) and "PostCS" region by Culham (2003). We suggest that this area may correspond to a human homologue of AIP (Binkofski et al., 1998; Culham et al., 2006; Frey et al., 2005; Lewis and Van Essen, 2000). These results suggest that AIP and VIP form a third tier of somatotopic maps that have multisensory properties. We might expect to find a more lateral part of AIP that represents the foot independent from those in PV, SII proper, and 7b. The evidence from Golaszewski et al. (2006) may be consistent with this idea.

\section{Conclusions}

Dodecapus, a computer-controlled MR-compatible system was constructed to automatically and independently deliver light air puffs to 12 locations on the body surface through a manifold inside the magnet. While we focused primarily on face stimulation, this flexible system can also deliver air puffs to lips, fingers and other body parts during the same scan. Two-condition block design paradigms were employed to localize the representations of the face, lips and fingers in the primary and secondary somatosensory, parietal, and motor cortices. Phase-encoded paradigms were then used to reveal the internal organization of the somatotopic maps in these areas. This system is easy and quick to set up, and could be useful for non-invasive somatotopic mapping in both basic and clinical studies.

\section{Acknowledgments}

We thank Rick Buxton, Eric Wong, Tom Liu, and Larry Frank at the UCSD fMRI Center for scan time, pulse sequences, and advice, Larry May for hardware support, Ronald Kurz for machine shop help, and Laura Kemmer for pilot experiments and comments. Supported by NSF BCS 0224321 (Sereno), NIH R01 NS41925 (E. Wong), NIH R01 NS36722 (R. Buxton), NIH R01 HD041581 (J. Stiles), and The Swartz Foundation (S. Makeig and T.-P. Jung). 


\section{References}

Alkadhi, H., Crelier, G.R., Boendermaker, S.H., Hepp-Reymond, M.C., Kollias, S.S., 2002. Somatotopy in the ipsilateral primary motor cortex. NeuroReport 13, 2065-2070.

Beauchamp, M.S., 2005. See me, hear me, touch me: multisensory integration in lateral occipital-temporal cortex. Curr. Opin. Neurobiol. $15,145-153$.

Beisteiner, R., Windischberger, C., Lanzenberger, R., Edward, V., Cunnington, R., Erdler, M., Gartus, A., Streibl, B., Moser, E., Deecke, L., 2001. Finger somatotopy in human motor cortex. NeuroImage 13, $1016-1026$.

Binkofski, F., Dohle, C., Posse, S., Stephan, K.M., Hefter, H., Seitz, R.J., Freund, H.J., 1998. Human anterior intraparietal area subserves prehension: a combined lesion and functional MRI activation study. Neurology 50, 1253-1259.

Blake, R., Sobel, K.V., James, T.W., 2004. Neural synergy between kinetic vision and touch. Psychol. Sci. 15, 397-402.

Blankenburg, F., Ruben, J., Meyer, R., Schwiemann, J., Villringer, A., 2003. Evidence for a rostral-to-caudal somatotopic organization in human primary somatosensory cortex with mirror-reversal in areas $3 \mathrm{~b}$ and 1. Cereb. Cortex 13, 987-993.

Borsook, D., Becerra, L., Fishman, S., Edwards, A., Jennings, C.L., Stojanovic, M., Papinicolas, L., Ramachandran, V.S., Gonzalez, R.G., Breiter, H., 1998. Acute plasticity in the human somatosensory cortex following amputation. NeuroReport 9, 1013-1017.

Borsook, D., Burstein, R., Becerra, L., 2004. Functional imaging of the human trigeminal system: opportunities for new insights into pain processing in health and disease. J. Neurobiol. 61, 107-125.

Briggs, R.W., Dy-Liacco, I., Malcolm, M.P., Lee, H., Peck, K.K., Gopinath, K.S., et al., 2004. A pneumatic vibrotactile stimulation device for fMRI. Magn. Reson. Med. 51, 640-643.

Burton, H., 2002. Cerebral cortical regions devoted to the somatosensory system: results from brain imaging studies in humans. In: Nelson (Ed.), The Somatosensory System: Deciphering the Brain's Own Body Image. CRC Press, Boca Raton.

Coq, J.-O., Qi, H., Collins, C.E., Kaas, J.H., 2004. Anatomical and functional organization of somatosensory areas of the lateral fissure of the New World titi monkey (Callicebus moloch). J. Comp. Neurol. 476, 363-387.

Corbetta, M., Burton, H., Sinclair, R.J., Conturo, T.E., Akbudak, E., McDonald, J.W., 2002. Functional reorganization and stability of somatosensory-motor cortical topography in a tetraplegic subject with late recovery. Proc. Natl. Acad. Sci. U. S. A. 99, 17066-17071.

Cox, R.W., 1996. AFNI: software for analysis and visualization of functional magnetic resonance neuroimages. Comput. Biomed. Res. 29, 162-173.

Cramer, S.C., Bastings, E.P., 2000. Mapping clinically relevant plasticity after stroke. Neuropharmacology 39, 842-851.

Cramer, S.C., Crafton, K.R., 2006. Somatotopy and movement representation sites following cortical stroke. Exp. Brain Res. 168, 25-32.

Cramer, S.C., Moore, C.I., Finklestein, S.P., Rosen, B.R., 2000. A pilot study of somatotopic mapping after cortical infarct. Stroke 31, 668-671.

Cramer, S.C., Benson, R.R., Burra, V.C., Himes, D., Crafton, K.R., Janowsky, J.S., 2003. Mapping individual brains to guide restorative therapy after stroke: rationale and pilot studies. Neurol. Res. 25, 811-814.

Culham, J.C., 2003. Human brain imaging reveals a parietal area specialized for grasping. In: Kanwisher, N., Duncan, J. (Eds.), Attention and Performance XX: Functional Brain Imaging of Human Cognition. Oxford Univ. Press, Oxford, UK.

Culham, J.C., Cavina-Pratesi, C., Singhal, A., 2006. The role of parietal cortex in visuomotor control: what have we learned from neuroimaging? Neuropsychologia 44, 2668-2684.

Dale, A.M., Fischl, B., Sereno, M.I., 1999. Cortical surface-based analysis. I. Segmentation and surface reconstruction. NeuroImage 9, 179-194.

DaSilva, A.F., Becerra, L., Makris, N., Strassman, A.M., Gonzalez, R.G., Geatrakis, N., Borsook, D., 2002. Somatotopic activation in the human trigeminal pain pathway. J. Neurosci. 22, 8183-8192.
Dechent, P., Frahm, J., 2003. Functional somatotopy of finger representations in human primary motor cortex. Hum. Brain Mapp. 18, 272-283.

Disbrow, E., Roberts, T., Krubitzer, L., 2000. Somatotopic organization of cortical fields in the lateral sulcus of Homo sapiens: evidence for SII and PV. J. Comp. Neurol. 418, 1-21.

Duhamel, J.R., Colby, C.L., Goldberg, M.E., 1998. Ventral intraparietal area of the macaque: congruent visual and somatic response properties. J. Neurophysiol. 79, 126-136.

Engel, S.A., Rumelhart, D.E., Wandell, B.A., Lee, A.T., Glover, G.H., Chichilniski, E.J., Shadlen, M.N., 1994. FMRI of human visual cortex. Nature 369, 525.

Francis, S.T., Kelly, E.F., Bowtell, R., Dunseath, W.J., Folger, S.E., McGlone, F., 2000. fMRI of the responses to vibratory stimulation of digit tips. NeuroImage 11, 188-202.

Fischl, B., Sereno, M.I., Dale, A.M., 1999. Cortical surface-based analysis. II. Inflation, flattening, and a surface-based coordinate system. NeuroImage 9, 195-207.

Frey, S.H., Vinton, D., Norlund, R., Grafton, S.T., 2005. Cortical topography of human anterior intraparietal cortex active during visually guided grasping. Brain Res. Cogn. Brain Res. 23, 397-405.

Friedman, D.P., Jones, E.G., Burton, H., 1980. Representation pattern in the second somatic sensory area of the monkey cerebral cortex. J. Comp. Neurol. 192, 21-41.

Gelnar, P.A., Krauss, B.R., Szeverenyi, N.M., Apkarian, A.V., 1998. Fingertip representation in the human somatosensory cortex: an fMRI study. NeuroImage 7, 261-283.

Gizewski, E.R., Koeze, O., Uffmann, K., de Greiff, A., Ladd, M.E., Forsting, M., 2005. Cerebral activation using a MR-compatible piezoelectric actuator with adjustable vibration frequencies and in vivo wave propagation control. NeuroImage 24, 723-730.

Golaszewski, S.M., Siedentopf, C.M., Baldauf, E., Koppelstaetter, F., Eisner, W., Unterrainer, J., et al., 2002a. Functional magnetic resonance imaging of the human sensorimotor cortex using a novel vibrotactile stimulator. NeuroImage 17, 421-430.

Golaszewski, S.M., Zschiegner, F., Siedentopf, C.M., Unterrainer, J., Sweeney, R.A., Eisner, W., et al., 2002b. A new pneumatic vibrator for functional magnetic resonance imaging of the human sensorimotor cortex. Neurosci. Lett. 324, 125-128.

Golaszewski, S.M., Siedentopf, C.M., Koppelstaetter, F., Fend, M., Ischebeck, A., Gonzalez-Felipe, V., et al., 2006. Human brain structures related to plantar vibrotactile stimulation: a functional magnetic resonance imaging study. NeuroImage 29, 923-929.

Graham, S.J., Staines, W.R., Nelson, A., Plewes, D.B., Mcllroy, W.E., 2001. New devices to deliver somatosensory stimuli during functional MRI. Magn. Reson. Med. 46, 436-442.

Graziano, M.S., Gandhi, S., 2000. Location of the polysensory zone in the precentral gyrus of anesthetized monkeys. Exp. Brain Res. 135, 259-266.

Hagen, M.C., Franzen, O., McGlone, F., Essick, G., Dancer, C., Pardo, J.V., 2002. Tactile motion activates the human middle temporal/V5 (MT/V5) complex. Eur. J. Neurosci. 16, 957-964.

Hanakawa, T., Parikh, S., Bruno, M.K., Hallett, M., 2005. Finger and face representations in the ipsilateral precentral motor areas in humans. J. Neurophysiol. 93, 2950-2958.

Harrington, G.S., Downs III, J.H., 2001. FMRI mapping of the somatosensory cortex with vibratory stimuli. Is there a dependency on stimulus frequency? Brain Res. 897, 188-192.

Harrington, G.S., Wright, C.T., Hunter Downs III, J., 2000. A new vibrotactile stimulator for functional MRI. Hum. Brain Mapp. 10, $140-145$.

Hayashi, T., Konishi, S., Hasegawa, I., Miyashita, Y., 1999. Mapping of somatosensory cortices with functional magnetic resonance imaging in anaesthetized macaque monkeys. Eur. J. Neurosci. 11, 4451-4456.

Hlustik, P., Solodkin, A., Gullapalli, R.P., Noll, D.C., Small, S.L., 2001. Somatotopy in human primary motor and somatosensory hand representations revisited. Cereb. Cortex 11, 312-321.

Hodge Jr., C.J., Huckins, S.C., Szeverenyi, N.M., Fonte, M.M., Dubroff, 
J.G., Davuluri, K., 1998. Patterns of lateral sensory cortical activation determined using functional magnetic resonance imaging. J. Neurosurg. 89, 769-779.

Huang, R.-S., Sereno, M., 2005. Mapping the human homologue of the ventral intraparietal area (VIP). NeuroImage 26, S23 (Suppl.).

Iannetti, G.D., Porro, C.A., Pantano, P., Romanelli, P.L., Galeotti, F., Cruccu, G., 2003. Representation of different trigeminal divisions within the primary and secondary human somatosensory cortex. NeuroImage 19, 906-912.

Jain, N., Qi, H.X., Catania, K.C., Kaas, J.H., 2001. Anatomic correlates of the face and oral cavity representations in the somatosensory cortical area $3 \mathrm{~b}$ of monkeys. J. Comp. Neurol. 429, 455-468.

Kaas, J.H., Nelson, R.J., Sur, M., Lin, C.S., Merzenich, M.M., 1979. Multiple representations of the body within the primary somatosensory cortex of primates. Science 204, 521-523.

Kaas, J.H, Jain, N., Qi, H.X., 2002. The organization of the somatosensory system in primates. In: Nelson (Ed.), The Somatosensory System: Deciphering the Brain's Own Body Image. CRC Press, Boca Raton.

Krubitzer, L., Clarey, J., Tweedale, R., Elston, G., Calford, M., 1995. A redefinition of somatosensory areas in the lateral sulcus of macaque monkeys. J. Neurosci. 15, 3821-3839.

Kurth, R., Villringer, K., Curio, G., Wolf, K.J., Krause, T., Repenthin, J., et al., 2000. fMRI shows multiple somatotopic digit representations in human primary somatosensory cortex. NeuroReport 11, 1487-1491.

Lee, C.C., Jack Jr., C.R., Riederer, S.J., 1998. Mapping of the central sulcus with functional MR: active versus passive activation tasks. Am. J. Neuroradiol. 19, 847-852.

Lee, C.C., Ward, H.A., Sharbrough, F.W., Meyer, F.B., Marsh, W.R., Raffel, C., 1999. Assessment of functional MR imaging in neurosurgical planning. Am. J. Neuroradiol. 20, 1511-1519.

Lewis, J.W., Van Essen, D.C., 2000. Corticocortical connections of visual, sensorimotor, and multimodal processing areas in the parietal lobe of the macaque monkey. J. Comp. Neurol. 428, 112-137.

Lotze, M., Erb, M., Flor, H., Huelsmann, E., Godde, B., Grodd, W., 2000. fMRI evaluation of somatotopic representation in human primary motor cortex. NeuroImage 11, 473-481.

Manger, P.R., Woods, T.M., Jones, E.G., 1996. Representation of face and intra-oral structures in area $3 \mathrm{~b}$ of macaque monkey somatosensory cortex. J. Comp. Neurol. 371, 513-521.

Manger, P.R., Woods, T.M., Munoz, A., Jones, E.G., 1997. Hand/Face border as a limiting boundary in the body representation in monkey somatosensory cortex. J. Neurosci. 17, 6338-6351.

McGlone, F., Kelly, E.F., Trulsson, M., Francis, S.T., Westling, G., Bowtell, R., 2002. Functional neuroimaging studies of human somatosensory cortex. Behav. Brain Res. 135, 147-158.

Merzenich, M.M., Kaas, J.H., Sur, M., Lin, C.S., 1978. Double representation of the body surface within cytoarchitectonic areas $3 \mathrm{~b}$ and 1 in "SI" in the owl monkey (Aotus trivirgatus). J. Comp. Neurol. 181, 41-73.

Miyamoto, J.J., Honda, M., Saito, D.N., Okada, T., Ono, T., Ohyama, K., Sadato, N., 2006. The representation of the human oral area in the somatosensory cortex: a functional MRI study. Cereb. Cortex 16, 669-675.

Moore, C.I., Stern, C.E., Corkin, S., Fischl, B., Gray, A.C., Rosen, B.R., Dale, A.M., 2000a. Segregation of somatosensory activation in the human rolandic cortex using fMRI. J. Neurophysiol. 84, 558-569.

Moore, C.I., Stern, C.E., Dunbar, C., Kostyk, S., Gehi, A., Corkin, S., 2000 b. Referred phantom sensations and cortical reorganization after spinal cord injury in humans. Proc. Natl. Acad. Sci. U. S. A. 97, 14703-14708.

Nakamura, A., Yamada, T., Goto, A., Kato, T., Ito, K., Abe, Y., Kachi, T., Kakigi, R., 1998. Somatosensory homunculus as drawn by MEG. NeuroImage 7, 377-386.

Nevalainen, P., Ramstad, R., Isotalo, E., Haapanen, M.L., Lauronen, L., 2006. Trigeminal somatosensory evoked magnetic fields to tactile stimulation. Clin. Neurophysiol. 117, 2007-2015.

Nguyen, B.T., Tran, T.D., Hoshiyama, M., Inui, K., Kakigi, R., 2004. Face representation in the human primary somatosensory cortex. Neurosci. Res. 50, 227-232.
Nguyen, B.T., Inui, K., Hoshiyama, M., Nakata, H., Kakigi, R., 2005. Face representation in the human secondary somatosensory cortex. Clin. Neurophysiol. 116, 1247-1253.

Nihashi, T., Kakigi, R., Okada, T., Sadato, N., Kashikura, K., Kajita, Y., Yoshida, J., 2002. Functional magnetic resonance imaging evidence for a representation of the ear in human primary somatosensory cortex: comparison with magnetoencephalography study. NeuroImage 17, $1217-1226$.

Overduin, S.A., Servos, P., 2004. Distributed digit somatotopy in primary somatosensory cortex. NeuroImage 23, 462-472.

Preuss, T.M., Stepniewska, I., Kaas, J.H., 1996. Movement representation in the dorsal and ventral premotor areas of owl monkeys: a microstimulation study. J. Comp. Neurol. 371, 649-676.

Ramachandran, V.S., 2005. Plasticity and functional recovery in neurology. Clin. Med. 5, 368-373.

Ramachandran, V.S., Rogers-Ramachandran, D., 2000. Phantom limbs and neural plasticity. Arch. Neurol. 57, 317-320.

Rijntjes, M., Tegenthoff, M., Liepert, J., Leonhardt, G., Kotterba, S., Muller, S., et al., 1997. Cortical reorganization in patients with facial palsy. Ann. Neurol. 41, 621-630.

Ruben, J., Schwiemann, J., Deuchert, M., Meyer, R., Krause, T., Curio, G., Villringer, K., Kurth, R., Villringer, A., 2001. Somatotopic organization of human secondary somatosensory cortex. Cereb. Cortex 11, 463-473.

Sato, K., Nariai, T., Sasaki, S., Yazawa, I., Mochida, H., Miyakawa, N., et al., 2002. Intraoperative intrinsic optical imaging of neuronal activity from subdivisions of the human primary somatosensory cortex. Cereb. Cortex 12, 269-280.

Sato, K., Nariai, T., Tanaka, Y., Maehara, T., Miyakawa, N., Sasaki, S., et al., 2005. Functional representation of the finger and face in the human somatosensory cortex: intraoperative intrinsic optical imaging. NeuroImage 25, 1292-1301.

Schwartz, T.H., Chen, L.M., Friedman, R.M., Spencer, D.D., Roe, A.W., 2004. Intraoperative optical imaging of human face cortical topography: a case study. NeuroReport 15, 1527-1531.

Sereno, M.I., Huang, R.-S., 2006. A human parietal face area contains aligned tactile and visual maps. Nat. Neurosci. 9, 1337-1343.

Sereno, M.I., Tootell, R.B.H., 2005. From monkeys to humans: what do we now know about brain homologies? Curr. Opin. Neurobiol. 15, $135-144$.

Sereno, M.I., Dale, A.M., Reppas, J.B., Kwong, K.K., Belliveau, J.W., Brady, T.J., et al., 1995. Borders of multiple visual areas in humans revealed by functional magnetic resonance imaging. Science 268, 889-893.

Sereno, M.I., Pitzalis, S., Martinez, A., 2001. Mapping of contralateral space in retinotopic coordinates by a parietal cortical area in humans. Science 294, 1350-1354

Servos, P., Zacks, J., Rumelhart, D.E., Glover, G.H., 1998. Somatotopy of the human arm using fMRI. NeuroReport 9, 605-609.

Servos, P., Engel, S.A., Gati, J., Menon, R., 1999. fMRI evidence for an inverted face representation in human somatosensory cortex. NeuroReport 10, 1393-1395

Stepniewska, I., Preuss, T.M., Kaas, J.H., 1993. Architectonics, somatotopic organization, and ipsilateral cortical connections of the primary motor area (M1) of owl monkeys. J. Comp. Neurol. 330, 238-271.

Stippich, C., Hofmann, R., Kapfer, D., Hempel, E., Heiland, S., Jansen, O., et al., 1999. Somatotopic mapping of the human primary somatosensory cortex by fully automated tactile stimulation using functional magnetic resonance imaging. Neurosci. Lett. 277, 25-28.

Stippich, C., Romanowski, A., Nennig, E., Kress, B., Hahnel, S., Sartor, K., 2004. Fully automated localization of the human primary somatosensory cortex in one minute by functional magnetic resonance imaging. Neurosci. Lett. 364, 90-93.

Talavage, T.M., Sereno, M.I., Melcher, J.R., Ledden, P.J., Rosen, B.R., Dale, A.M., 2004. Tonotopic organization in human auditory cortex revealed by progressions of frequency sensitivity. J. Neurophysiol. 91, $1282-1296$. 
van Westen, D., Fransson, P., Olsrud, J., Rosen, B., Lundborg, G., Larsson, E.M., 2004. Fingersomatotopy in area $3 b$ : an fMRI-study. BMC Neurosci. 20, 5-28.

Wu, C.W.-H., Kaas, J.H., 2003. Somatosensory cortex of prosimian Galagos: physiological recording, cytoarchitecture, and corticocortical connections of anterior parietal cortex and cortex of the lateral sulcus. J. Comp. Neurol. 457, 263-292.
Yang, T.T., Gallen, C.C., Schwartz, B.J., Bloom, F.E., 1993. Noninvasive somatosensory homunculus mapping in humans by using a large-array biomagnetometer. Proc. Natl. Acad. Sci. U. S. A. 90, 3098-3102.

Zappe, A.C., Maucher, T., Meier, K., Scheiber, C., 2004. Evaluation of a pneumatically driven tactile stimulator device for vision substitution during fMRI studies. Magn. Reson. Med. 51, 828-834. 